\title{
COMPANHIA DE APRENDIZES MARINHEIROS DE SERGIPE: ALGUMAS CONSIDERAÇÕES SOBRE CORPO E GÊNERO
}

\author{
Solyane Silveira Lima ${ }^{1}$
}

\section{RESUMO}

A escrita do presente trabalho tem como objetivo principal analisar as questões que versam sobre a História do Corpo e sobre as questões de gênero na Companhia de Aprendizes Marinheiros de Sergipe. Esta instituição militar iniciou suas atividades em abril de 1868 e tinha o objetivo de atender os meninos órfãos e desvalidos maiores de sete anos. Seu intuito era que eles servissem de mão de obra especializada à Marinha e ao Brasil.Tal instituição estava destinada à formação específica de marujos e funcionava como escola em regime de internato. Nela, oficialmente os aprendizes tinham direito à alimentação, fardamento, material escolar, soldo mensal, bem como assistência médica e religiosa. Para alcançar nosso objetivo, estruturamos o texto em três momentos. Inicialmente dissertaremos a respeito de algumas discussões sobre as prescrições para o corpo na escola e sobre gênero. Em seguida sobre a instituição militar sergipana e sua atuação como viveiro de formação de pessoal para a Armada. Por fim, demonstro os artifícios utilizados pela Companhia de Marinheiros para disciplinarizar crianças e jovens do sexo masculino com o intuito de torná-los sujeitos úteis a si e a pátria, utilizando como base as prescrições médicas e higienistas para pôr em prática os ideais de modernidade anunciados pela República. Dessa maneira, concluímos que não apenas existia o controle e poder sobre os aprendizes marinheiros, mas também quão intensa era a disciplina dentro da instituição.Ressalta-se que a presente análise está alicerçada nas contribuições do sociólogo Norbert Elias e do filósofo Michel Foucault. As fontes utilizadas foram: legislação nacional, relatos de governo, mensagens presidenciais, correspondências e ofícios diversos.

Palavras-chave: Instituição. Educação do Corpo. Gênero.

${ }^{1}$ Pós-Doutoranda em Educação na Universidade Tiradentes (UNIT). Doutora em Educação pela Universidade Federal de Minas Gerais - UFMG. Email: solylima@hotmail.com 


\section{ABSTRACT \\ Companhia de Aprendizes Marinheiros de Sergipe: some considerations on body and gender}

The writing of this paperaims to analyze the issues that deal with the history of the Bodyand the issues of gender in the Companhia de AprendizesMarinheiros de Sergipe. This military institution began operations in April 1868 and had the objective of serving the destitute orphan boys and largest of seven years. His intention was that they would serve as skilled labor to the Navy and to Brazil. Such an institution was destined to specific training of sailors and functioned as a boarding school. It officially learners were entitled to food, uniforms, school supplies, a monthly stipend and medical and religious assistance. To achieve our goal, we have structured the text in three stages. Initiallywrite about some discussions on prescriptions for body in school and gender. Then write about the Sergipe military institution and its role as a nursery for training of personnel for the Navy. Finally, we demonstrate the tricks used by the Companhia de Marinheiros to discipline children and young males in order to make them useful to themselves and subject the country, using as a basis the medical prescriptions and hygienists to implement the ideals of modernity announced by Republic. Thus, we conclude that there was not only the control and power over the sailors apprentices, but also how intense was the discipline within the institution. It is emphasized that this analysis is based on the contributions of the sociologist Norbert Elias and philosopher Michel Foucault. He sources used were: national legislation, government reports, presidential messages, correspondence, and various crafts.

Keywords: Institution. Education of the Body. Gender. 


\section{Introdução}

Ao observarmos a História da Educação Brasileira podemos verificar que desde o século XIX médicos higienistas voltavam suas atenções para o cuidado com o corpo na escola, a sua física, sua forma e robustez, daí a necessidade de sua disciplinarização através da ginástica e da Educação Física. Segundo Foucault (1987), a disciplina pode ser entendida como métodos que permitem o controle do corpo, que realizam a sujeição constante de suas forças impondo-lhes uma relação de docilidade-utilidade, ou seja, fórmulas gerais de dominação. "A disciplina fabrica assim corpos submissos e exercitados, corpos dóceis". (1987, p. 119).

Para além dessa questão, estes profissionais também demonstraram preocupação com a arquitetura dos edifícios, a quantidade de alunos, a alimentação, em geral. Aspectos que se enquadravam no campo das preocupações médico-higiênicas e religiosas.

Com a expansão da medicina, a escola e a educação tornaram-se agentes privilegiados, pois acreditava-se que para formar as novas gerações seria necessária uma intervenção não apenas no espaço público da escola, mas também, no espaço privado da casa, portanto, pais e mestres se constituem nos principais destinatários das prescrições médicas quando se trata de educação. Percebe-se então,

[...] a presença de um discurso médico-científico que procurava normatizar a escola a partir de uma clínica médica. Desse modo, os doutores brancos, letrados e da elite prescreveram um tratamento cuidadoso e minucioso para a escola, de modo a poder formar um individuo higienizado, sem vícios. Um indivíduo normalizado e normalizador, equipado com a nova sensibilidade (GONDRA, 2004, p. 478).

Essa ordem médica no interior da educação escolar pode ser compreendida tanto como defesa da necessidade de escolas, como um modo moderno ou iluminista de instalação desse novo modelo de formação de homens. Pois, educar nessa perspectiva, passava a exigir a invenção de uma nova organização a ser instalada em obediência aos imperativos da nova sociedade que se queria fundar, na qual a escola deveria concorrer para favorecer o estabelecimento de um processo de formação a longo prazo e que se constituísse em uma experiência útil à nova ordem. 
"A escola, dessa forma, foi elevada à condição de lugar de produção de um sujeito sadio e, por extensão, de uma sociedade curada/higienizada; em outras palavras, de uma sociedade regenerada por intermédio da organização escolar, assim inventada pelos médicos". (GONDRA, 2004, p. 479).

Dessa maneira, a higiene forneceria o modelo de organização escolar baseado na razão médica, retirando assim do espaço privado o monopólio sobre a formação da infância concebendo a educação como um remédio que seria responsável pela instalação de uma nova era, uma era civilizada.

A construção de uma ordem civilizada nos trópicos constituiuse em um sonho dos homens da ciência médica no Brasil do século XIX. Homens cujos olhos e ouvidos voltados para um mundo considerado civilizado recusavam-se a aceitar a vida e a parte das condições do país em que viviam e no qual muitos deles haviam nascido e se formado.

[...]

Esse movimento, rumo a uma remodelação da escola, tinha no horizonte a utopia de produzir uma sociedade escolarizada, regenerada e homogênea. Uma escola e uma sociedade higienizada (GONDRA, 2000, p. 543).

Isso só seria possível através da educação, pois que, educar e civilizar convergia para um único fim, que seria o de produzir um futuro regenerado e sem vícios, fundamentado no discurso da racionalidade médico-higiênica.

Consoante Norbert Elias, "Até certo ponto, o conceito de civilização minimiza as diferenças nacionais entre povos: enfatiza o que é comum a todos os seres humanos ou - na opinião dos que o possuem - deveria sê-lo." (ELIAS, 1994, p. 25). Não há dúvidas que a educação escolar se apresenta como elemento fundamental para o desenvolvimento da civilização na perspectiva da auto coerção, refinamento de atitudes, apaziguamento, abrandamento das pulsões e racionalização dos hábitos.

Assim a civilidade torna-se uma pedagogia do comportamento privado e também público ao combinar a aprendizagem das boas maneiras com as bases da instrução elementar. $\mathrm{O}$ processo civilizador seria então uma transformação de estruturas individuais. 
Espera-se que as crianças atinjam um nível de controle das emoções, que formem certos padrões de vergonha, comedimento e pudor capazes de lhes auxiliar no recalque das pulsões - que quer dizer crescimento, habilitando-as ao convívio social. (LEÃO, 2007, p. 11)

A proposta higienista visava o desenvolvimento de ações profiláticas voltadas para a constituição de uma sociedade saudável e submetia as crianças a um treinamento que por meio da regularidade de hábito aprendessem a ser disciplinadas com a pretensão de se produzir sujeitos higiênicos e higienizados, ocorrendo assim à união do Estado com a Medicina.

Para o Estado, a educação assumiria um cunho nitidamente social, tomando para si a incumbência do educar. Para a medicina, a criança passa a ser vista sob a ótica da higiene social, que elegia a proposta higienista como razão para a proteção de todas as crianças. "Assim o discurso médico interveio socialmente, prescrevendo medidas educacionais que pretendiam conformar o social para fins determinados, como higienizar as práticas escolares" (GONDRA, 2004, p. 13).

Esse movimento em prol da educação e higienização dos corpos e mentes contava com o respaldo de médicos, bacharéis e educadores. $\mathrm{E}$ por meio da escola, esperava-se conduzir o país a reformas que gerassem progresso e desenvolvimento, colocando-o na condição de "nação moderna".

Disciplinar não é mais prevenir ou corrigir. É moldar. É contar com a plasticidade da natureza infantil, com sua adaptabilidade, com sua capacidade natural de ajustamento a fins postos pela sociedade. Por isso [...] conta-se com o poder disciplinador das novas exigências postas nos novos ritmos que a técnica e a máquina imprimem a sociedade (CARVALHO, 2003, p. 308).

No campo educacional, modernidade significava incorporar métodos científicos às práticas pedagógicas. Assim, saúde e educação apresentavam-se para seus agentes como questões indissociáveis. No campo da saúde firma-se a convicção de que medidas de política sanitária seriam ineficazes se não abrangessem a introjeção, nos sujeitos, de hábitos higiênicos por meio da educação e no movimento educacional, a saúde é um dos pilares da grande campanha de regeneração nacional pela educação. 
Dentro dessa perspectiva de cientificidade, modernidade e disciplinarização dos corpos é que se encontra a Companhia de Aprendizes Marinheiros de Sergipe, instituição militar fundada sob a justificativa de que atenderia ao grande número de meninos desvalidos que lá existia. Considerando que "a inscrição dos gêneros - feminino ou masculino - nos corpos é feita, sempre, no contexto de uma determinada cultura" (LOURO, 2000, p. 11), é possível vislumbrar como o disciplinamento operado por tal companhia era voltado para a produção e o governo de corpos, especificamente, de meninos.

\section{A Companhia de Aprendizes Marinheiros de Sergipe}

De acordo com os Relatórios dos Presidentes de Província, esta Instituição foi pleiteada por alguns Presidentes desde o início da década de 1860, sob a justificativa de que promoveria o atendimento às crianças e jovens órfãos existentes em Sergipe (RELATÓRIO, 1960). Em 20 de junho de 1864, assumia a presidência da Província Cincinato Pinto da Silva, que permaneceu no cargo até 1865.

Assim como o presidente que o antecedeu, Dr. Thomaz Alves Júnior, Cincinato Pinto da Silva também solicitou ao Ministro da Marinha a criação de uma Companhia de Aprendizes Marinheiros para Sergipe. Segundo ele, existia uma quantidade imensa de crianças que, por falta dos pais e de meios de subsistência, vagavam ociosas pelas praias e povoados, deixando de frequentar as escolas e a igreja. Por isso, era necessário educá-las e moralizá-las e, em sua opinião, nenhuma instituição seria mais proveitosa que a de Aprendizes Marinheiros.

V. Ex ${ }^{a}$. pode ficar bem certo de que uma quantidade imensa de
crianças, já por falta de seus pais, já por falta de meios, vagam
ociosas pelas nossas praias e povoados deixando de frequentar
as escolas bem como a Igreja por não terem vestiário, nem a
necessária alimentação, e neste abandono vivem embrutecidas,
até que um dia, quando escaparão da morte, aqui a maior fonte
é levada pelo alimento que toma, ou vem a ser soldados, e mais
soldados, ou então, não tendo tido correção a sua perversa
índole, entregam-se ao crime, e terminam seus dias em uma
prisão.
Esse futuro desastroso do órfão desamparado desaparecerá
desde que se esta Província tiver uma escola em que possa
colocá-los, onde, recebendo educação apropriada, se tornem
úteis ao seu país e nenhuma delas é mais proveitosa do que a de 
Aprendizes Marinheiros (Arquivo Nacional, ref.: XM - 69 1859-1887).

De acordo com o presidente, as Companhias de Aprendizes Marinheiros seriam o melhor meio para o progresso da Marinha, bem como para a prosperidade das províncias, especialmente das que abrem canal de navegação costeira com o alto mar. Assim sendo, as crianças aprenderiam desde cedo o amor pela vida marítima, transformando-se posteriormente em marinheiros preparados para servir ao país.

Mas, apesar de todo esforço e apelo do presidente, a província continuou sem este estabelecimento até 1868, ano em que foi inaugurada a Companhia de Aprendizes Marinheiros de Sergipe, na administração de Antônio D'Araujo D'Aragão Bulcão que assim se expressou em seu relatório sobre a criação da Companhia de Aprendizes Marinheiros na Província de Sergipe:

Sob o comando do Capitão do Porto acha-se a Companhia de Aprendizes Marinheiros, criada nesta província pelo Decreto $\mathrm{n}^{\circ}$ 4.142 de 05 de abril último. Atualmente existem alistados 18 menores.

Fiz quanto pude no sentido de dar incremento a mesma Companhia que franqueou em Sergipe um melhor futuro a tantos infelizes que por aí existem abandonados aos horrores da miséria. Desde que se aboliram os falsos preconceitos incutidos no espírito do povo, a Companhia prosperará (RELATÓRIO, 1868).

Portanto, criada em 29 de Fevereiro de 1868, pelo Decreto Imperial n $^{\mathbf{o}}$ 4.112, a Companhia de Aprendizes Marinheiros de Sergipe visava o atendimento de crianças abandonadas e carentes. Além da promoção de mão-de-obra especializada, diminuindo os índices de criminalidade favorecendo uma formação básica nas primeiras letras e nos fazeres de marinheiros.

Essa Companhia obedeceu aos mesmos objetivos e regulamentos das outras 17 instituições ${ }^{2}$. Funcionava como uma escola em regime de internato, onde oficialmente, os aprendizes tinham direito a alimentação, fardamento, material escolar, soldo mensal, assistência médica e religiosa. Instalou-se sob o comando do Capitão dos Portos

\footnotetext{
${ }^{2}$ Rio de Janeiro (1840), Pará e Bahia (1855), Mato Grosso, Pernambuco e Santa Catarina (1857), Maranhão e Rio Grande do Sul (1861), Espírito Santo (1862), Paraná e Ceará (1864), Santos (1868), Paraíba e Amazonas (1871), Rio Grande do Norte (1872), Piauí (1873) e Alagoas (1875). (CAMINHA, 2002, p. 48).
} 
numa casa particular que não oferecia nenhuma comodidade e registrou uma matrícula inicial de apenas 21 alunos.

Seu funcionamento era regulado pelas disposições do Decreto $\mathrm{n}^{\circ} 1.517$ de 04 de Janeiro de 1855, que definia o seu público alvo, condições de acesso, educação oferecida, permanência, dentre outros elementos. Nos Artigos 15, 16 e 17, estão definidas as propostas para a formação dos aprendizes na associação entre instrução e formação para o trabalho.

Art. 15. A instrução militar dos Aprendizes Marinheiros começará por aprenderem a entrar em forma, perfilar, volver à direita e à esquerda, marchar a passo ordinário e dobrado, até a escola de pelotão; o manejo das armas brancas, a nomenclatura da parlamenta, carreta e peças de artilharia, e o uso que tem cada um desses instrumentos.

Art. 16. A instrução náutica consistirá em aprenderem os misteres relativos à arte de Marinheiro, como fazer pinhas, costuras, alças, nós, coser pano, entalhar e, finalmente, aparelhar e desaparelhar um navio.

Esta instrução poderá ser adquirida na Casa do aparelho e nas Velas do Arsenal, ou a bordo de algum dos Navios, que estacionarem na Província.

Art. 17. Menores aprenderão também a ler, escrever, contar, riscar mapas, e a Doutrina Cristã, servindo-lhes de mestre o Capelão do Arsenal, ou um oficial Marinheiro, que tiver as habilitações necessárias (IMPÉRIO, 1855).

De acordo com o Presidente da Província, em 1875, a Companhia de Aprendizes Marinheiros de Sergipe oferecia instrução militar, técnica e primária às crianças e jovens desamparados:

Instrução Primária dos aprendizes

Dirige-se o ensino primário dos aprendizes o Reverendo João Ponciano dos Santos.

Pelo adiantamento que apresenta os meninos reconheço que este sacerdote tem sido zeloso no cargo que ali exerce.

Instrução Militar

Atualmente os aprendizes recebem a que é determinada pelo art. 15 do Regulamento orgânico, e com algum aproveitamento. Instrução Técnica

Recebem os menores a que se pode dar em uma província que não tem um arsenal marítimo e onde não aportam navios do Estado; por isso sua aprendizagem restringe-se ao que é recomendado pelo art. 16, com exceção da última parte (RELATÓRIO, 1875, p. 73).

Conforme podemos observar, a educação proposta evidenciava os interesses da Marinha na preparação de mão de obra para seus serviços, além de se tratar de uma instituição pensada e destinada às 
crianças pobres. Porém, apenas àquelas que atendessem ao perfil desejado para o serviço da Armada.

No ano seguinte da sua criação o índice de matrícula foi de 26 alunos, dado que representou o preconceito social dominante e o receio da população quanto à eminente ameaça de recrutamento para a Guerra do Paraguai, provocando um lento crescimento do número de aprendizes. Segundo Venâncio,

Entre 1840 e 1864, as Companhias de Aprendizes viveram anos de notável expansão e de prestígio. A partir da Guerra do Paraguai essa situação sofre uma brusca inversão, instalando-se um clima de desconfiança por parte das camadas populares. [...] [...] a Marinha começou a esvaziar as Companhias de Aprendizes, enviando os meninos para os batalhões navais. [...] A situação que então se inaugura é a do recrutamento forçado, do recrutamento a todo custo. As diversas instituições destinadas a meninos maiores de sete anos, a começar pelas Companhias de Aprendizes, passam a ser alvo de um assédio sem tréguas.

[...]

A guerra inaugurava assim um novo período na vida das Companhias de Aprendizes Marinheiros. Sinal desses novos tempos foi a brusca diminuição dos "voluntários a prêmio" (VENÂNCIO, 2004, p. 202-205) .

Apenas em 1876 foi que se verificou uma maior aceitação da população, nesse período a Companhia Sergipana contava com a matrícula de 81 alunos. Fato que levou a Vice-Presidente da Província a afirmar que:

A repugnância que ao princípio manifestou o povo em admitir os seus filhos menores na Companhia de Aprendizes vai desaparecendo, tem alcançado que os meninos são bemtratados, educados com desvelo e adquirem conhecimentos de um meio de vida decente para os futuros dias (RELATÓRIO, 1877).

A Companhia de Aprendizes Marinheiros de Sergipe funcionou até 1885 e seu fechamento aconteceu em decorrência do elevado gasto que onerava aos cofres públicos em função do seu quadro efetivo estar sempre aquém do número desejado. Foi através do Decreto nº 9.371 de 14 de fevereiro de 1885 que as Companhias foram reduzidas, reorganizadas e administradas por um novo regulamento, passando a denominar-se Escolas de Aprendizes Marinheiros, com o fim de educar e preparar marinheiros para os diversos serviços da marinha, sendo reduzidas nacionalmente, de 18 para 12 Escolas. 
Decorridos vinte anos do seu fechamento, a instituição volta a funcionar em 1905 com o nome de Escola de Aprendizes Marinheiros, obedecendo à nova organização estabelecida pelo Decreto $n^{\circ} 9.371$ de 14 de Fevereiro de $1885^{3}$ e conforme o Decreto ${ }^{\circ} 5532$ de 05 de Maio de 1905. Nesse momento, sua proposta educacional sofreu algumas alterações, dentre elas: a idade do menor foi modificada para 13 a 16 anos, o ensino foi dividido em elementar e profissional e incentivou-se a entrada de aprendizes já alfabetizados.

A criação dessas Companhias (que posteriormente receberam o nome de escolas) foi uma tentativa que a Marinha Brasileira encontrou para oferecer marinheiros qualificados para servir a nação. Porém para formar esse marinheiro eram necessários a disciplinarização e manipulação do corpo, bem como o treinamento desses aprendizes. Sobre esse assunto versará o próximo e último tópico.

\section{"Ser cidadão brasileiro, de constituição robusta e própria para a vida no mar"}

A Companhia de Aprendizes Marinheiros de Sergipe, como todas as outras, era uma escola em sistema de internato, modelo que se apresenta como um regime de educação adequado ao exercício e controle da disciplina. De acordo com Foucault (1987), o controle disciplinar não consiste simplesmente em ensinar ou impor uma série de gestos definidos, mas sim impor a melhor relação entre um gesto e a atitude global do corpo, para garantir sua condição de eficácia e de rapidez.

Sendo assim, a inspeção fazia-se presente a partir da chegada do menor à Companhia para verificar se atendiam aos pré-requisitos estabelecidos pelo Decreto $\mathrm{n}^{\circ} 1.517$ de 04 de Janeiro de 1855 , bem como, a possibilidade de transformação daqueles aprendizes em

\footnotetext{
${ }^{3}$ Anterior à criação da Escola de Aprendizes Marinheiros de Sergipe em 1905, houve duas tentativas frustradas de instauração dessa instituição no Estado. A primeira em 1889, com o Decreto n. 10.238 de 02 de maio de 1889, que criava a Escola, mas por falta de verba não foi possível a sua concretização. E a segunda ocorreu em 1904 a partir do Decreto n. 1186 de 15 de junho de 1904 que autorizava o poder executivo a restabelecer esta Escola. Porém isso só aconteceu em 1905, conforme o Decreto $\mathrm{n}^{\circ}$ 5532 de 05 de Maio de 1905.
} 
futuros marinheiros. Por isso era preciso que atendessem as seguintes exigências:

\begin{abstract}
Art. $8^{\circ}$. Para ser admitido como aprendiz marinheiro era necessário: "ser cidadão brasileiro, ter idade entre 10 e 17 annos, ser de constituição robusta e própria para a vida no mar". Art. $9^{\circ}$. Também poderiam ser admitidos menores de 10 anos de idade que apresentassem desenvolvimento físico suficiente para começar o aprendizado.

Art. $10^{\circ}$ e $11^{\circ}$. As vagas eram preenchidas por voluntários ou contratados a prêmio, matriculados por pais ou tutores; por órfãos e desvalidos que, possuindo os requisitos solicitados, fossem remetidos pelas autoridades competentes designadas pelo Presidente da Província: Juízes de órfãos e autoridades policiais.

A Companhia oferecia instrução militar, náutica e elementar (IMPÉRIO, 1855).
\end{abstract}

Para ingressar na instituição, os menores eram avaliados pelo médico e pelo comandante da Companhia, a fim de verificar se eles estavam aptos ou não para o serviço. Isso significava não apresentar nenhuma moléstia e possuir uma boa constituição física a ser desenvolvida. Depois do ritual de inspeção, ocorria o assentamento. A entrada de menores na Companhia acontecia a qualquer momento e podiam ser encaminhados por várias pessoas, desde os próprios pais ou tutores, até mesmo pelo Presidente da Província ou pelo Juiz de Menores.

Seu aquartelamento era em prédio próprio. Apesar de ter sido construído para tal fim, não atendia às necessidades da Companhia, nem apresentava capacidade para comportar o número de aprendizes estimados (200 praças). Além de se tornar insalubre e pouco ventilado no inverno, a área ocupada pelo estabelecimento não oferecia espaço para os exercícios e, tampouco, para recreio dos menores nas horas de folga.

Por esse motivo, em 1876, o Presidente da Província, João Ferreira d'Araujo Pinho, solicita ao Ministro da Marinha um navio para que servisse de quartel-escola aos aprendizes. E, em 1878, encontrava-se a Companhia sergipana aquartelada no "PatachoIguassu". Seu antigo prédio passou a acomodar a enfermaria dos menores.

${ }^{4}$ De acordo com informações obtidas na Diretoria do Patrimônio Histórico e Documentação da Marinha DPHDM-RJ, esse navio apresentava as seguintes características: Embarcação à vela e aparelhada em patacho, construída nos estaleiros particulares da ponta da areia, em Niterói, sob os planos do Engenheiro naval 
A Companhia funciona a bordo do patacho "Iguassú", que depois dos últimos consertos feitos está em condições de satisfazer o fim a que se destina.

São incontestáveis os relevantes serviços que prestam instituições desta ordem, e satisfaz-me em declarar que a companhia desta província acha-se em prospero estado (RELATÓRIO, 1878, p. 42).

Dentro da Companhia de Aprendizes Marinheiros, a primeira regra que se impunha aos menores era a disciplina do tempo, tirando deles a sua noção particular e obrigando-os a ter uma noção homogênea. Dessa forma, os sujeitos eram coletivizados a partir da introspecção da noção do tempo que se impunha na distribuição dos diversos afazeres diários, dentre eles: alvorada, limpeza do quartel, banho e natação, lavagem de roupa, baldeação, instrução primária, instrução náutica, instrução militar, almoço, jantar, recreio (exercício de ginástica) e recolhimento.

O tempo medido e pago deve ser também um tempo sem impureza nem defeito, um tempo de boa qualidade, e durante todo o seu transcurso o corpo deve ficar aplicado a seu exercício. A exatidão e a aplicação são, com a regularidade, as virtudes fundamentais do tempo disciplinar.

$[\ldots]$

O tempo penetra o corpo, e com ele todos os controles minuciosos do poder (FOUCAULT, 1987, p. 129).

A distribuição do tempo, a duração das diferentes atividades e as penalidades aplicadas aos menores pelas faltas cometidas eram atribuições do Comandante da Companhia, sendo que aos aprendizes eram aplicados castigos mais brandos que aos marinheiros

Napoleão Level. Tinha as seguintes características: 92 pés de comprimento, 24 de boca, 7 de pontal e, de calado, 7,5 pés. Foi lançado ao mar a 13 de maio de 1858 . Foi artilhado com quatro canhões de calibre 30 em bateria, e guarnecido com 48 praças. A 25 de junho do mesmo ano foi-lhe passada mostra de armamento, recebendo o seu comando o primeiro-tenente Joaquim Francisco Chaves. Velejou para o Rio da Prata a $1^{\circ}$ de setembro e regressou a 23 de agosto de 1863. O Patacho suspendeu âncoras, com destino a Mato Grosso, a 10 de janeiro de 1864, retornando a 8 de setembro do mesmo ano. Aos 13 de outubro, assumiu o seu comando o primeiro-tenente Manuel Ricardo da Cunha Couto. A 25 de janeiro de 1865, seguiu para o Rio da Prata, voltando a 8 de abril. Velejou para aquele destino, a 7 de julho. A 2 de outubro de 1866, encontrava-se fundeado na boca da Lagoa Pires, no Paraguai, sob o comando do capitão-tenente Eduardo Wanderkolk. Ali pescou um torpedo inimigo. Em outubro de 1869, sob o comando do capitão-tenente Frederico Guilherme de Lorena, encontrava-se em Montevidéu, carecendo de reparos. Passou mostra de armamento a 21 de abril de 1875. No ano seguinte, encontramo-lo servindo de quartel a Companhia de Aprendizes de Marinheiro de Sergipe. Em data de $1^{\circ}$ de fevereiro 1882 a Secretaria de Marinha comunicava haver a Presidência do referido Estado feito entrega, em 9 de janeiro, do casco e mais objetos do navio, que foram vendidos em vale pública. 
propriamente ditos. De acordo com as informações contidas no Art. 38 do Decreto $\mathrm{n}^{\circ} 1.517$ de 04 de janeiro de 1855, os aprendizes eram castigados com prisão simples, solitária, privação temporária de parte da ração e guardas e sentinelas dobradas.

De acordo com Foucault (1987) os castigos disciplinares têm a função de reduzir os desvios, sendo, por isso mesmo, corretivo. Em suma, a arte de punir, no âmbito do poder disciplinar, não visa nem a expiação, nem mesmo a repressão, mas sim a normalização. Portanto, era através das penalidades que se permitia capturar o corpo e exercer sobre ele uma coerção.

A Reforma de 1907 impinge novo regulamento às Escolas de Aprendizes Marinheiros por meio do Decreto N. 6582 de 1 de agosto de 1907 e a disciplina é reforçada através do sistema de recompensas. Nesse sentido, os aprendizes poderiam passar o mês de férias na casa dos pais ou tutores, sendo necessário que os responsáveis solicitassem isso por escrito ao comandante e que não houvesse nenhuma inconveniência registrada por parte dos menores (Art. 79).

Foram conferidas aos aprendizes notas mensais de comportamento na seguinte escala: aos que não incorrerem em pena alguma, nem forem admoestados - ótimo; aos que incorrerem até a $2^{\mathrm{a}}$ pena - bom; até a $3^{\mathrm{a}}$ pena - regular; até a $4^{\mathrm{a}}$ - mau; até a $5^{\mathrm{a}}$ e $6^{\mathrm{a}}$ pena - péssimo. Além das notas, os menores usariam um distintivo especial que indicava os mais disciplinados, conforme o $\S 2^{\circ}$ do Art. 42:

Os aprendizes que tiverem nota - ótimo - durante um trimestre usarão no braço esquerdo, à meia altura, como distintivo especial, uma estrela de pano vermelho cosida na blusa de flanela ou de ganga, e de pano azul na blusa branca.

Os que tiverem a nota - bom - durante um trimestre usarão como distintivo um $\mathrm{V}$ voltado para cima, na mesma posição e condições do acima indicado. Qualquer pena imposta fará perder o direito ao uso do distintivo correspondente, durante um trimestre (MARINHA, 1908).

Pode-se verificar que ao longo dos regulamentos citados a questão da disciplina nas instituições de aprendizes marinheiros esteve presente, a maneira de exercê-la, porém, muda com o passar dos anos. A disciplina que pune também gratifica, e as recompensas deveriam ser estimuladas em vez do castigo. Muda-se a estratégia, mas a coerção sob os aprendizes em nome da disciplina militar perdurará por toda a existência dessa instituição. 


\section{Considerações Finais}

Corroborando com o pensamento de Foucault de que a disciplina não pode ser identificada como uma instituição nem com um aparelho, mas que ela é um tipo de poder, uma modalidade para exercê-lo, podemos constatar a sua existência na Companhia de Aprendizes Marinheiros de Sergipe, bem como, quão forte era o controle e o poder que ela exercia sobre os meninos lá matriculados.

Vale ainda ressaltar a diversidade de artifícios e estratégias que foram postos em prática não apenas pelos comandantes da instituição, mas também pelos Presidentes de Província e pelo governo Imperial através dos Ministros da Marinha, visando a formação das crianças e jovens desvalidos em mão de obra especializada para os quadro da Armada.

Por fim, gostaria de retomar a questão inicial deste artigo e frisar como as prescrições médicas no final dos oitocentos influenciaram os fazeres das instituições educativas e como esses profissionais se apropriaram das questões higienistas para colocar em prática os ideais de modernidade anunciados pela República.

\section{Referências}

CAMINHA, Henrique Marque. Organização do pessoal da Marinha Imperial. In.: Marinha do Brasil. História naval brasileira. Rio de Janeiro: SDGM, 2002, 3v.

CARVALHO, Marta Maria Chagas de. Quando a história da educação é a história da disciplina e da higienização das pessoas. In: FREITAS, Marcos Cezar (org.). História social da infância no Brasil. São Paulo, Cortez. 2003.

ELIAS, Norbert. O processo civilizador: uma história dos costumes. V. 1. Rio de Janeiro: Jorge Zahar Editor, 1994.

FOULCAULT, Michel. Vigiar e punir: nascimento da prisão. Petrópolis, Vozes, 1987. 
GONDRA, José Gonçalves. Artes de Civilizar: Medicina, Higiene e Educação Escolar na Corte Imperial. Rio de Janeiro: EdUERJ, 2004.

GONDRA, José G. Medicina, higiene e educação escolar. In: LOPES, Eliane Marta Teixeira; FARIA FILHO, Luciano Mendes; VEIGA, Cynthia Greive (orgs.). 500 anos de educação no Brasil. Belo Horizonte: Autêntica, 2000.

LEÃO, Andréa Borges. Norbert Elias e a educação. Belo Horizonte: Autêntica, 2007.

LOURO, Guacira Lopes. Pedagogias da sexualidade. In: LOURO, Guacira (org.). O corpo educado: pedagogias da sexualidade. 2. ed. Belo Horizonte: Autêntica. 2007, p.1-34.

ROCHA, Heloisa Helena Pimenta. Prescrevendo regras de bem viver: cultura escolar e racionalidade científica. Cadernos CEDES, 52. Campinas: UNICAMP, 2000.

VENÂNCIO, Renato Pinto. Os aprendizes da guerra. In: DEL PRIORI, Mary. História das crianças no Brasil. São Paulo: Contexto, 2004.

\section{Legislação}

IMPÉRIO. Colleção das Leis do Império do Brasil de 1836. Rio de Janeiro. Typographia de Silva, 1838.

Decreto $\mathrm{n}^{\text {o }}$ 1. 517 de 04/01/1855. Colleção das Leis do Império do Brasil. 1855.

Decreto $n^{\text {o }}$ 4. 142 de 05/04/1868. Colleção das Leis do Império do Brasil. 1868.

Decreto $n^{\circ}$ 9. 371 de 14/02/1885.Colleção das Leis do

Império do Brasil. 


\section{Documentos}

RELATÓRIO apresentado à Assembléia Geral Legislativa na sessão ordinário de 1840, pelo Ministro e Secretário de Estado dos Negócios da Marinha, Jacinto Roque de Sena Pereira. Rio de Janeiro, Typographia Nacional, 1840.

RELATÓRIO apresentado à Assembléia Legislativa Provincial de Sergipe no dia 2 de março de 1868 pelo Exm. Senhor. Presidente, dr.Antonio de Araujo d'Aragão Bulcão. Aracaju, Typ. do Jornal de Sergipe, 1868.

RELATÓRIO apresentado à Assembléia Legislativa Provincial de Sergipe no dia $1^{\circ}$ de março de 1869 pelo Rxm. Snr. Presidente, dr. Evaristo Ferreira da Veiga. Aracaju, Typ. do Jornal de Sergipe, 1869.

RELATÓRIO com que o exm. snr.dr.Antonio dos Passos Miranda abriu a Assembléia Legislativa Provincial de Sergipe no dia $1^{\circ}$ de março de 1875. Aracajú, Typ. do Jornal do Aracajú, 1875.

RELATÓRIO com que o exm. snr.dr. José Martins Fontes, $1^{\circ}$ vicepresidente da província, abriu a $2^{\mathrm{a}}$ sessão da $21^{\mathrm{a}}$ legislatura da Assembléia Legislativa Provincial, no dia 6 de março de 1877. Sergipe, Typ. do Jornal do Aracaju, 1877.

RELATÓRIO com que o exm. snr.dr. José Martins Fontes, $1^{\circ}$ vicepresidente, abriu a $1^{\mathrm{a}}$ sessão da $22^{\mathrm{a}}$ legislatura da Assembléia Provincial de Sergipe no dia $1^{\circ}$ de março de 1878. Aracaju, Typ. do Jornal do Aracaju. 1878.

RELATÓRIO apresentado ao Presidente da República dos Estados Unidos do Brasil pelo Contra-almirante J. Pinto da Luz Ministro de Estado dos Negócios da Marinha em abril de 1902. Rio de Janeiro, Imprensa Nacional, 1902. (referente ao ano de 1901)

RELATÓRIO apresentado ao Presidente da República dos Estados Unidos do Brasil pelo Contra-almirante Julio César de Noronha, Ministro de Estado dos Negócios da Marinha em abril de 1903. Rio de Janeiro, Imprensa Nacional, 1903. (referente ao ano de 1902). 


\section{Documentos avulsos}

Arquivo Nacional. Ref.: XM - 69 (1859-1887). Correspondência de 21/01/1965, do Presidente da Província Cincinato Pinto da Silva ao Ministro e Secretário de Estado dos Negócios da Marinha Francisco Xavier Pinto Lima. 